\title{
Supplier Evaluation with Environmental Aspects and Common DEA Weights
}

\author{
Gyöngyi Vörösmarty ${ }^{1 *}$ Imre Dobos² \\ ${ }^{1}$ Department of Logistics and Supply Chain Management, Faculty of Business Administration, Corvinus University of Budapest, \\ 1093 Budapest, Fővám tér 8., Hungary \\ 2 Department of Economics, Faculty of Economic and Social Sciences, Budapest University of Technology and Economics, \\ 1111 Budapest, Magyar Tudósok Körútja 3., Hungary \\ *Corresponding author, e-mail: gyongyi.vorosmarty@uni-corvinus.hu
}

Received: 12 December 2017, Accepted: 04 December 2018, Published online: 28 January 2019

\begin{abstract}
Supplier selection is an important business decision. Beside traditional management criteria the environmental aspects are getting often recognition. In this paper the method of Data Envelopment Analysis (DEA) is used to study the extension of traditional supplier selection methods with environmental factors. The focus will be on the weight selection process which can control the selection. In this method we divide the criteria in two manners: the traditional and environmental (green) factors. Then with the help of DEA we are searching a weight system with which the environmental criteria can influence the decision with a representation of the green factors. To choose the mentioned weight system, we apply DEA (Data Envelopment Analysis) with common weights analysis (CWA) method. In this case of DEA/CWA the common weights are calculated with a linear programming problem.
\end{abstract}

\section{Keywords}

green supplier assessment, DEA, common weights analysis, multi-criteria decision making

\section{Introduction}

Environmental issues are getting more recognition in business nowadays. It is widely accepted that in a supply chain context green management covers performance of the whole chain which calls for the consideration of the environmental performance of the suppliers as well.

The means of supplier management have gone through a major development over the last twenty years. Large number of studies was carried out which focus on supplier assessment, as the performance management of suppliers called for more sophisticated solutions for evaluation and measurement.

The supplier selection methods are widely examined in the literature with multi-criteria decision analysis models. These models contain such techniques, as analytic hierarchy process (AHP), analytic network process (ANP), or data envelopment analysis (DEA) etc. (Agarwal et al., 2011; Simić et al., 2017)

The aim of this paper is to contribute to sustainable supplier assessment methods. In our analysis we introduce the green criteria such as carbon emission in the supplier evaluation and we examine effect of changes on the selected supplier and on bid evaluation. Most of the methods use a kind of weight scores analyses. In our model we have chosen one of the multi-criteria decision-making methods namely the Data Envelopment Analysis (DEA). The proposed model helps the decision maker (purchaser) to compare the bids and to consider the effects of changes of the bids. The proposed model also helps group decision making to consider the effects of the different values of the group members (e.g. financial and environmental aspects).

This paper will be organised as follows. First a brief literature review will be provided on supplier assessment criteria, methods of green assessment and the categorisation of supplier. After the literature review a case example will be analysed. The Data Envelopment Analysis is applied to investigate the effects of environmental criteria in decision making processes. In our example the changes in the role of environmental criteria (e.g. carbon emission and recycling) will be compared. It will be examined that how the change of carbon emission in the supplier bid will affect the relative weight factors. In our example we analyse only one decision making unit to demonstrate 
the functioning of the basic DEA model. In the classical, basic DEA model the decision maker must solve as many linear programming models, as the number of the decision making units. Then we present the common weights analysis (CWA) method. In this model we must solve only one linear programming model, which essentially reduces the computation time to determine the efficient decision making units. Finally, the result of the paper will be summarised.

\section{Supplier assessment in literature}

The literature on supplier evaluation and assessment is extensive (e.g. Araz and Ozkarahan, 2007; Sinha and Anand, 2017; Talluri and Narasimhan, 2004) although terminology is not always defined how these terms relate to each other. In this paper the term 'supplier assessment' will be used, in a sense that it is a management activity with the primary aim of acquiring information to analyse and to manage supplier relationships and supply situations. Within this aim Stannack and Osborn (1997) identified three important objectives or purposes, some of which may be contradictory. They identified these as: assessment for selection (to choose the best supplier); assessment for control (management and planning) and assessment for development (supplier ranking is clearly useful as a motivational tool). Assessment for selection is perhaps the most commonly known form, however as purchasing management is playing a rather proactive than reactive role the other two aims are getting more attention. The review of literature of supplier assessment will cover 3 topics: first how the assessment criteria evolved, how environmental aspects can be incorporated in the evaluation, second the evaluation methods of green supplier assessment, third to highlight the diversity of purchasing situations purchasing portfolio methods will be referred to and their implication on supplier assessment.

\subsection{Criteria of supplier assessment}

Supplier assessment rests upon the development of criteria. These criteria will be embedded in the environment in which they are developed. The most common assessment criteria have changed over time. According to Dickson (1966) the most important categories in the 1960s were the quality, delivery, performance history, warranties and claim policies, production facilities and capacities, price, technical capability, financial position. A later study of Weber et al. (1991) ranked quality as of extreme importance, net price, delivery, production facilities and capacity, technical capability, financial position, performance history, warranties and claims as of important criteria. It was just later that environmental factor as part of assessment criteria were discussed. Since the mid $90^{\prime}$ several studies were published with the aim of providing a structured picture of assessment criteria. Noci (1997) suggested a preliminary framework that identifies 4 groups of measures for assessing environmental performance as green competencies, current environmental efficiency, supplier's green image and net life cycle cost. Handfield et al. (2002) identified as the top 10 most important criteria to measure supplier's environmental performance as:

1. public disclosure of environmental record,

2. second tier supplier environmental evaluation,

3. hazardous waste management,

4. toxic waste pollution management,

5. on EPA 17 hazardous material list,

6. ISO 14000 certified,

7. reverse logistics program,

8. environmentally friendly product packaging,

9. ozone depleting substances,

10. hazardous air emissions management.

Humphreys et al. (2003) also developed a framework for incorporating environmental criteria into the supplier selection process. In their construct they identified quantitative (e.g. environmental friendly material, environmental costs), and qualitative environmental criteria (e.g. management competencies, green image, design for environment).

During the last years based on these frequently cited articles the criteria was investigated by many other publications. (e.g. Chai et al., 2013; Kumar Kar and Pani, 2014; Rezaei et al., 2016)

These studies exemplify that researchers formulated frameworks for comprehensive assessment of suppliers. The frameworks provided by them support supplier selection; however, they can be used for the other two goals of assessment: they might serve control and development purposes as well. These models provide support to overview critical aspects of supplier performance, however they seldom help the selection process (the identification of the decision criteria). Our paper will close this gap as it highlights the role of weights in decision process.

\subsection{Methodology of supplier assessment}

The supplier assessment methodology receives substantial attention in literature. Papers are diverse according to their 
aims and to the applied mathematical instruments. Several assessment methods were developed to incorporate green aspects in supplier management decisions, in this paper only a few of them is featured. Beside the classical supplier evaluation methods (the categorical method, weighted-point method) Noci (1997), lists the matrix approach, vendor profile analysis and Analytic Hierarchy Process. Enarsson (1998) used the fishbone diagram as an evaluation tool. Araz and Ozkarahan (2007) developed a new multicriteria sorting method based on Promethee methodology. Narasimhan et al. (2001) proposes a methodology for evaluation to assist supplier development, with the help of DEA they identify supplier clusters. Hsu and Hu (2009) present an analytic network process (ANP) approach to incorporate the issue of hazardous substance management (HSM) into supplier selection. Bai and Sarkis (2010) also aims to help supplier development by introducing a formal model using rough set theory to investigate the relationships between organizational attributes, supplier development program involvement attributes, and performance outcomes. In their model the performance outcomes focus on environmental and business dimensions.

Current publications often suggest complex methodology. Rezaei et al. (2016) proposes a three-phase supplier selection methodology. Conjunctive screening is used for pre-selection, the best worst method (BWM), a novel multiple criteria decision-making method is introduced for the selection phase. Material price and annual quantity are integrated with the decision at the aggregation phase. They use both economic and environmental criteria and propose a comprehensive green supplier selection model. The analytic network process (ANP) is used to deal with the interdependencies among the criteria, and the traditional Grey relational analysis (GRA) has been modified to better address the uncertainties inherent in supplier selection decisions. They utilize the ANP and an improved GRA to weight the criteria and rank the suppliers respectively. Hashemi et al. (2015) use both economic and environmental criteria and propose a comprehensive green supplier selection model. They use the analytic network process (ANP) to deal with the interdependencies among the criteria, and the traditional Grey relational analysis (GRA) is utilised to weight the criteria and rank the suppliers respectively.

The above referred literature provides frameworks with comprehensive solutions. This implies that incorporation of environmental criteria in supplier selection often calls for sophisticated methodology.

\subsection{The diversity of the purchasing situation and its implication to the assessment}

One of the most important statements of literature on purchasing and supply management is that supply situations are not alike. A number of portfolio models try to provide structures to evaluate the supply situation or the position of the buyer. They also call attention to the distinct management of the diverse situations. Perhaps the most well-known method is the Kraljic matrix (Kraljic, 1983), which categorises the purchased items into four groups according strategic importance of the items and the complexity of supply market (many author uses the matrix with the factor of supply risk instead of the complexity of the supply market). A similar model was developed by Van Weele (2009), who provided a structured management approach to each four categories. The matrix of Bensaou (1999) is also frequently referred in the literature, in which the structuring factors are the supplier specific investments of the buyer and the buyer specific investments of the supplier. The environmental aspects are not explicitly involved in these portfolios; however, they can be easily incorporated in the dimensions. (E.g. it can be considered to be a form of supply risk.) There is an enhanced version of the Kraljic matrix (Krause et al., 2009), which deals with the incorporation of sustainability criteria and calls attention to diverse approach and management attention to the categories.

Beside diverse purchasing situations there are other factors e.g. company size, which may influence the purchasing practice of a company. Literature draws a distinction between a person and an organisation or a firm acquires goods and services. (Van Weele, 2009) The purchasing processes of firms are based on rationale logic, sophisticated methodology (e.g. application of the above methodology) and the decision is in most of the cases made by a group. The purchasing courses and publications mostly focus on their practice; they are capable to apply the above mentioned sophisticated management tools of supplier assessment. The small and medium sized companies (SME) are different. Because of their size and processes, they can be considered as organisational buyers (they make purchasing decisions based on rational management criteria), however in most of the cases it is not possible for them to use sophisticated purchasing methodology e.g. they do have the know-how or the organisational specialisation as the large companies. Because of the large number of these companies and the importance for the economy many recent studies focus on the practice 
of SME and many of them investigate their purchasing practice (Ellegaard, 2009; Knudse and Servais, 2007; Morrissey and Pittaway, 2004). As these firms in most of the cases are not capable to use sophisticated management tools, they are not able to use sophisticated methodology for assessing the environmental activity of the suppliers.

\subsection{Summarizing the result of literature}

The above brief review of literature was intended to highlight that there is a gap in research interests. Most of the research in the topic of how to incorporate environmental aspects into supplier assessment focuses on the high importance purchasing situations or suggest a methodology which is demanding in terms of expertise and work hours. There is a lack of models applicable in those purchasing situations, when the lack of time or the relatively low importance of the purchased item does not justify the time consuming procedures or involvement of experts.

This paper suggests that the overall impact of those situations when the purchasing is not important or the risk is not high is significant and should be considered. Especially in a number of cases it is not possible or affordable to use currently available complex (perhaps time consuming or costly) methodologies. This is mainly why in practice it is still the weighted points method, which is mostly used by practitioners to assess the performance of suppliers. Beside the methodological weaknesses (as subjectivity of weights, incoherent measurement) weighted point method has several advantages from practical point of view: it is easy to understand the calculation, requires only basic mathematical knowledge, and quickly provides output.

\section{DEA Framework for weight selection}

Because of its easy application the scoring model is of practical importance in purchasing management. It makes it relevant to investigate its applicability. The selection of weights in most of the cases happens in advance as part of a group decision; however very often reflect subjective judgement. One of the most important limitations of this method that weights for various supplier performance attributes used in the weighted, additive scoring model are arbitrary set (Markovits-Somogyi, 2011; MarkovitsSomogyi et al., 2011; Narasimhan et al., 2001). Thus the final ranking of the supplier is heavily dependent on the assignment of these weights, which are often difficult to specify in an objective manner. In this section with the help of DEA we intended to develop a framework to assist the selection of the weights in a way to allow the control the result of the selection process. Our goal is to choose such weights which affect the results of the selection process.

The supplier selection model is formulated, as a decision making problem. Let us assume that the suppliers are evaluated along management and environmental criteria. (Dobos and Vörösmarty, 2014) The management criteria are the usual supplier evaluation criteria, such as purchasing price, lead time, or quality of the supplied products etc. The environmental criteria are listed in the previous section of this paper. We assume that the environmental criteria are the outputs of the examined model. A very common method is used to investigate the effects of environmental issues on the supplier assessment.

\subsection{The application of the basic DEA model in supplier selection}

The basic DEA method was initiated by Charnes et al. (1978) to determine the efficiency of decision making units (DMU). The model offered by them is a hyperbolic programming model under linear conditions. A general solution method of such kind of models was first investigated by Martos (1964) who examined the problem as a special case of linear programming model. The application is based on the categories "inputs", "outputs", and, efficiencies. Method DEA is a general framework. It is used in many management areas (Dénes et al., 2017; Koltai et al., 2017) including supplier evaluation. (Dobos and Vörösmarty, 2018; Ho et al., 2010)

The aim of the presented DEA model is to construct the weights for the management (input) and environmental (output) criteria. The weights are vectors $v$ and $u$ for the management and environmental criteria. Let us assume that the purchaser evaluates $p$ number of suppliers. The number of traditional management criteria is $\mathrm{n}$ and the number of environmental criteria is $\mathrm{m}$. The evaluation of supplier $\mathrm{i}$ is defined with vectors $\left(\mathbf{x}_{i}, \mathbf{y}_{i}\right)$, where vector $\mathrm{xi}$ is the value of the management criteria and vector $\mathbf{y}_{i}$ is the environmental criteria.

Let us formulate the DEA model in the next form, assumed that we examine the efficiency of the $1^{\text {th }}$ decision making unit:

$$
\mathbf{u} \cdot \mathbf{y}_{1} / \mathbf{v} \cdot \mathbf{x}_{1} \rightarrow \max
$$

s.t.

$\mathbf{u} \cdot \mathbf{y}_{j} / \mathbf{v} \cdot \mathbf{x}_{j} \leq 1 ; j=1,2, \ldots p$.

$\mathbf{u} \geq 0, \mathbf{v} \geq 0$. 
Model Eq. (1)-(3) is the basic model of the method DEA which can be reformulated in a linear programming model in the following form:

$\mathbf{u} \cdot \mathbf{y}_{1} \rightarrow \max$

s.t.

$\mathbf{v} \cdot \mathbf{x}_{1}=1$,

$\mathbf{u} \cdot \mathbf{y}_{j}-\mathbf{v} \cdot \mathbf{x}_{j} \leq 0 ; j=1,2, \ldots p$.

$\mathbf{u} \geq 0, \mathbf{v} \geq 0$

Model Eq. (4)-(7) can be solved with a commercial software, e.g. with Microsoft Excel Solver. Throughout the paper we apply this software to construct our numerical examples (see Table 1). Our example fulfils the general rule for the number of decision making units, to get proper results. Because the number of suppliers is equal to 15 , i.e. $p=\max \{m \times n ; 3 \times(m+n)\}$, where $p$ is the number of suppliers and numbers $m$ and $n$ are the number of outputs and inputs. (Cooper et al., 2001)

Let us transform the data of the table 1 in that form that fits better to maximization criterion, i.e. it gives a higher value than that of a less good evaluation. If a better evaluation has a higher value, than we do not change the evaluation of that criterion. (It is the case e.g. for the reusability, lead time and price.) If a better criterion gets a lower value, than we have two possibilities to build a new table: either we choose a negative sign before the given data, or we use the inverse of the data. In our analysis we have chosen the second solution to handle this problem. The new, transformed table is now (Table 2).

The linear programming model gives the following weights solving the problem for the first supplier (Table 3).

The DEA efficiency measures are shown in Table 4. The most efficient decision making units with maximal values of one are the $7^{\text {th }}, 8^{\text {th }}$, and $15^{\text {th }}$ suppliers. The first supplier in our case has an efficiency score of 0.950895 which is relatively high.

In our numerical example two set of criteria were formulated: management (traditional purchasing criteria) and environmental criteria.

The weights vector suggests that the weight of all classical purchasing aspects should be incorporated in the evaluation of the suppliers. The reusability aspect received a weight in the analysis, but criteria $\mathrm{CO} 2$ emission is not relevant in the supplier selection. In this evaluation situation the reverse logistic subsystem of the vendor should receive such a weight that highly influences the selection decision.
Table 1 Data for numerical example

\begin{tabular}{|c|c|c|c|c|c|}
\hline \multirow[b]{2}{*}{ Supplier } & \multicolumn{3}{|c|}{ Management criteria } & \multicolumn{2}{|c|}{ Environmental criteria } \\
\hline & $\begin{array}{l}\text { Lead } \\
\text { time } \\
\text { (Day) }\end{array}$ & $\begin{array}{c}\text { Quality } \\
(\%)\end{array}$ & $\begin{array}{l}\text { Price } \\
(\$)\end{array}$ & $\begin{array}{c}\text { Reusability } \\
(\%)\end{array}$ & $\begin{array}{c}\mathrm{CO} 2 \\
\text { emission } \\
(\mathrm{g} / \mathrm{t})\end{array}$ \\
\hline 1 & 2 & 80 & 2 & 70 & 30 \\
\hline 2 & 1 & 70 & 3 & 50 & 10 \\
\hline 3 & 3 & 90 & 5 & 60 & 15 \\
\hline 4 & 1.5 & 85 & 1 & 40 & 20 \\
\hline 5 & 2.5 & 75 & 2.5 & 65 & 35 \\
\hline 6 & 2 & 95 & 4 & 90 & 25 \\
\hline 7 & 3 & 80 & 1.5 & 75 & 15 \\
\hline 8 & 1.5 & 85 & 3.5 & 85 & 20 \\
\hline 9 & 1 & 70 & 3.5 & 55 & 10 \\
\hline 10 & 2.5 & 75 & 4 & 45 & 10 \\
\hline 11 & 3.5 & 90 & 2.5 & 80 & 25 \\
\hline 12 & 2 & 65 & 1.5 & 50 & 20 \\
\hline 13 & 3 & 85 & 3 & 75 & 15 \\
\hline 14 & 1.5 & 70 & 4.5 & 85 & 20 \\
\hline 15 & 1 & 65 & 2 & 75 & 15 \\
\hline
\end{tabular}

Table 2 The transformed data

\begin{tabular}{|c|c|c|c|c|c|}
\hline \multirow[b]{2}{*}{ Supplier } & \multicolumn{3}{|c|}{ Management criteria } & \multicolumn{2}{|c|}{ Environmental criteria } \\
\hline & $\begin{array}{l}\text { Lead } \\
\text { time } \\
\text { (Day) }\end{array}$ & $\begin{array}{c}\text { Quality } \\
(\%)\end{array}$ & $\begin{array}{l}\text { Price } \\
(\$)\end{array}$ & $\begin{array}{c}\text { Reusability } \\
(\%)\end{array}$ & $\begin{array}{c}\mathrm{CO} 2 \\
\text { emission } \\
(\mathrm{g} / \mathrm{t})\end{array}$ \\
\hline 1 & 2 & $1 / 80$ & 2 & 70 & $1 / 30$ \\
\hline 2 & 1 & $1 / 70$ & 3 & 50 & $1 / 10$ \\
\hline 3 & 3 & $1 / 90$ & 5 & 60 & $1 / 15$ \\
\hline 4 & 1.5 & $1 / 85$ & 1 & 40 & $1 / 20$ \\
\hline 5 & 2.5 & $1 / 75$ & 2.5 & 65 & $1 / 35$ \\
\hline 6 & 2 & $1 / 95$ & 4 & 90 & $1 / 25$ \\
\hline 7 & 3 & $1 / 80$ & 1.5 & 75 & $1 / 15$ \\
\hline 8 & 1.5 & $1 / 85$ & 3.5 & 85 & $1 / 20$ \\
\hline 9 & 1 & $1 / 70$ & 3.5 & 55 & $1 / 10$ \\
\hline 10 & 2.5 & $1 / 75$ & 4 & 45 & $1 / 10$ \\
\hline 11 & 3.5 & $1 / 90$ & 2.5 & 80 & $1 / 25$ \\
\hline 12 & 2 & $1 / 65$ & 1.5 & 50 & $1 / 20$ \\
\hline 13 & 3 & $1 / 85$ & 3 & 75 & $1 / 15$ \\
\hline 14 & 1.5 & $1 / 70$ & 4.5 & 85 & $1 / 20$ \\
\hline 15 & 1 & $1 / 65$ & 2 & 75 & $1 / 15$ \\
\hline
\end{tabular}

Table 3 Solution of the DEA model for the first supplier

\begin{tabular}{ccccc}
\hline Lead time & Quality & Price & Reusability & CO2 emission \\
\hline 0.096167 & 39.86104 & 0.154701 & 0.013584 & 0 \\
\hline
\end{tabular}




\begin{tabular}{lc} 
Table 4 Efficiency measures of the suppliers \\
\cline { 2 - 2 } Supplier & Efficiency \\
\hline 7 & 1 \\
8 & 1 \\
15 & 1 \\
6 & 0.993378 \\
1 & 0.950895 \\
11 & 0.931831 \\
13 & 0.83403 \\
14 & 0.818994 \\
5 & 0.762071 \\
4 & 0.707599 \\
12 & 0.654577 \\
9 & 0.618966 \\
2 & 0.601224 \\
3 & 0.541597 \\
10 & 0.439554 \\
\hline
\end{tabular}

It was presented in this numerical example that $\mathrm{CO} 2$ emission is so high that it is not decision relevant, i.e. the weight of this factor does not influence the selection process. Let us investigate the $\mathrm{CO} 2$ emission of the first supplier as a parameter. In this sensitivity analysis it was examined that how high $\mathrm{CO} 2$ emission level will be decision relevant. This means that the $\mathrm{CO} 2$ level was parameterized in the DEA linear programming problem in the goal function. (Gal, 1995)

Figure 1 shows the function of the factor weight in dependence on the carbon emission levels. This function is a decreasing one, which highlights how lowering carbon emission level influence decision.

This example shows that the reusability criterion is more effective than the $\mathrm{CO} 2$ emission level, as measure of environmental effects.

\subsection{The application of DEA/CWA in supplier selection}

The fundamental problem of the basic, classical DEA model is that the weight system differs from decision making unit to decision making unit, solving the linear programming problems. To handle this deficiency, a number of authors offer new DEA-type models. Roll and Golany (1993) propose to use weight restriction models to look for a common weight. Kao and Hung (2005) apply the method of compromise programming to search for a possible weight system. Unfortunately, the model proposed by them leads to nonlinear parametric programming model, which can be difficult to solve with numerical methods.

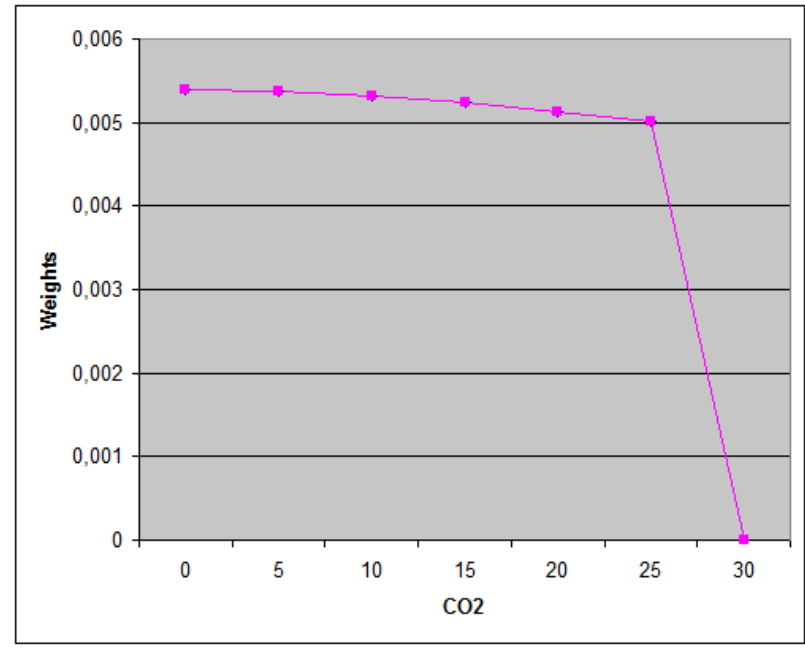

Fig. 1 Decision weight factors in dependence on carbon emission $(\mathrm{g} / \mathrm{t})$

Considering the difficulty of the mentioned models, we follow a different way.

The method of common weights analysis was introduced by Liu and Peng (2008), and Liu et al. (2006). The method is widely discussed in the decision making literature. (E.g. Jahanshahloo et al., 2010) In the following we present this model.

Let us use the linear programming problem Eq. (4)-(7) for the case, when the sum of inequalities Eq. (6) is maximised. The problem Eq. (4)-(7) can be reformulated in the following form Eq. (4')-(7'):

$\mathbf{u} \cdot \mathbf{Y} \cdot \mathbf{1}-\mathbf{v} \cdot \mathbf{X} \cdot \mathbf{1} \rightarrow \max$

s.t.

$\mathbf{v} \cdot \mathbf{1}=\mathbf{1}$,

$\mathbf{u} \cdot \mathbf{Y}-\mathbf{v} \cdot \mathbf{X} \leq 0$,

$\mathbf{u} \geq 0, \mathbf{v} \geq 0$.

In problem Eq. (4')-(7') vectors $\mathbf{1}$ are the summation vectors with elements one, matrices $\mathbf{Y}$ and $\mathbf{X}$ are the input and output matrices of the decision making units in the following form

$\mathbf{Y}=\left[\mathbf{y}_{1}, \mathbf{y}_{2}, \ldots, \mathbf{y}_{p}\right], \mathbf{X}=\left[\mathbf{x}_{1}, \mathbf{x}_{2}, \ldots, \mathbf{x}_{p}\right]$.

Equality (5') guarantees the boundedness of the set of the weight. Inequalities (6') subsume the efficiency indices. Goal function Eq. (4') summarizes the deviations from the maximal efficiency. The solution of problem Eq. (4')-(7') are the common weights for the supplier selection problem, but this is only the first stage of the 
ranking of suppliers. The next, second phase determines the efficiency of the decision making units (suppliers).

In the second phase of the evaluation of supplier, we construct the dual problem of Eq. (4')-(7'). In the dual problem Eq. (8)-(11) we use the shadow prices, as a measure of efficiency of decision making units. The dual problem now is:

$$
\lambda^{\prime} \rightarrow \min
$$

s.t.

$\mathbf{Y} \cdot \lambda \geq \mathbf{Y} \cdot 1$

$-\mathbf{X} \cdot \lambda+\lambda^{\prime} \cdot 1 \geq-\mathbf{X} \cdot 1$

$\lambda \geq 0, \lambda^{\prime} \in \mathfrak{R}$.

The optimal solution of problem Eq. (8)-(11) are shadow prices $\lambda=\left[\lambda_{1}, \lambda_{2}, \ldots \lambda_{p}\right]$. If we rank the shadow prices of the suppliers in a decreasing order, then the most efficient decision making unit is the one with the highest shadow price. With this method suppliers can be ordered after its efficiency. The benefit of this method is that we need not solve $p$ pieces of linear programming problems, only one, and the weights can be used for every other decision making units.

Let us apply the DEA/CWA method for our numerical example. The optimal solution gives the common weights of problem Eq. (4')-(7'), as shown in Table 5.

The DEA efficiency measures of the suppliers are presented in Table 6.

The optimal solution of problem Eq. (8)-(11) is zero in our case, but only five decision making units have a positive shadow price. In such a model all of the supplier must be involved in the second phase. The optimal shadow prices which are the optimal solution of problem Eq. (8)(11) are presented in Table 6, as well.

The most preferred decision making units are suppliers 4, 6, 7, 9, and 9. We have calculated the DEA efficiency measures with the common weight, too. Suppliers 6, 7, and 9 have a maximal efficiency measure, so we can conditionally choose these decision making units.

But there does not exist always a nonnegative solution for this system. With this numerical example we have demonstrated the applicability of DEA/CWA method on supplier selection and evaluation.
Table 5 The DEA/CWA weights

\begin{tabular}{ccccc}
\hline Lead time & Quality & Price & Reusability & CO2 emission \\
\hline 0.000603 & 0.998908 & 0.00049 & 0.000104 & 0.108891 \\
\hline
\end{tabular}

Table 6 Efficiency measures of the suppliers in a CWA context

\begin{tabular}{lcc}
\hline Supplier & DEA Efficiency & Shadow price $\left(\lambda_{\mathrm{i}}\right)$ \\
\hline 1 & 0.74167 & 0 \\
2 & 0.983287 & 0 \\
3 & 0.877547 & 0 \\
4 & 0.72939 & 0 \\
5 & 0.613385 & 0 \\
6 & 1 & 3.374568 \\
7 & 1 & 1.209523 \\
8 & 0.991652 & 0 \\
9 & 1 & 3.02606 \\
10 & 0.926523 & 0 \\
11 & 0.876013 & 0 \\
12 & 0.613839 & 0 \\
13 & 1 & 5.855218 \\
14 & 0.820004 & 0 \\
15 & 0.886655 & 0 \\
\hline
\end{tabular}

\section{Conclusion}

Environmental criteria are widely used in supplier selection systems. In this paper we investigated the influence of weights on the selection decision. Our contribution with the example is that in certain situation some criteria should be much overweighed to allow real influence on the selection process. The presented numerical example explained how the changes of $\mathrm{CO} 2$ emission level of a supplier effected the supplier's position in the assessment process.

A purchaser (decision maker) can influence a decision (supplier selection) with the choice of weight system. In our numerical example we can determine that the environmental criterion $\mathrm{CO} 2$ is irrelevant in the decision process, so it can be omitted in the decision making.

In a next paper a sensitivity analysis can be carried out to demonstrate the usability this concept of multi-criteria decision making methods. With easy software program based on a Microsoft Excel Solver the effects of the change of purchaser's opinion can be applied to solve such kind of decision problems.

\section{Acknowledgements}

The authors thank for the support of NKFIH K124 644. 


\section{References}

Agarwal, P., Sahai, M., Mishra, V., Bag, M., Singh, V. (2011) "A review of multi-criteria techniques for supplier evaluation and selection", International Journal of Industrial Engineering Computations, 2, pp. 801-810.

https://doi.org/10.5267/j.ijiec.2011.06.004

Araz, C., Ozkarahan, I. (2007) "Supplier evaluation and management system for strategic sourcing based on a new multicriteria sorting procedure", International Journal of Production Economics, 106(2), pp. 585-606.

https://doi.org/10.1016/j.ijpe.2006.08.008

Bai, C., Sarkis, J. (2010) "Green supplier development: analytical evaluation using rough set theory", Journal of Cleaner Production, 18(12), pp. $1200-1210$.

https://doi.org/10.1016/j.jclepro.2010.01.016

Bensau, M. (1999) "Portfolios of Buyer- Supplier Relationships", Sloan Management Review, 40(4), pp. 35-44.

Charnes, V., Cooper, W. W., Rhodes, E. (1978) "Measuring the efficiency of decision making units", European Journal of Operational Research, 2(6), pp. 429-444. https://doi.org/10.1016/0377-2217(78)90138-8

Chai, J., Liu, J. N. K., Ngai, E. W. T. (2013) "Application of decision-making techniques in supplier selection: A systematic review of literature", Expert Systems with Applications, 40(10), pp. 3872-3885. https://doi.org/10.1016/j.eswa.2012.12.040

Cooper, W. W., Li, S., Seiford, L. M., Tone, K., Thrall, R. M., Zhou, J. (2001) "Sensitivity and Stability Analysis in DEA: Some Recent Developments", Journal of Productivity Analysis, 15, pp. 217-246. https://doi.org/10.1023/A:1011128409257

Dénes, R. V., Kecskés, J., Koltai, T., Dénes, Z. (2017) "The Application of Data Envelopment Analysis in Healthcare Performance Evaluation of Rehabilitation Departments in Hungary", Quality Innovation Prosperity, 21(3), pp. 127-141. https://doi.org/10.12776/qip.v21i3.920

Dickson, G. W. (1966) "An Analysis of Vendor Selection Systems and Decisions", Journal of Purchasing, 2(1), pp. 5-17.

Dobos, I., Vörösmarty, Gy. (2014) "Green supplier selection and evaluation using DEA-type composite indicators", International Journal of Production Economics, 157, pp. 273-278. https://doi.org/10.1016/j.ijpe.2014.09.026

Dobos, I., Vörösmarty, G. (2018) "Evaluating green suppliers: improving supplier performance with DEA in the presence of incomplete data", Central European Journal of Operations Research, pp. 1-13. https://doi.org/10.1007/s10100-018-0544-9

Ellegaard, C. (2009) "The purchasing orientation of small company owners", Journal of Business \& Industrial Marketing, 24(3/4), pp. 291-300. https://doi.org/10.1108/08858620910939831

Enarsson, L. (1998) "Evaluation of suppliers: how to consider the environment", International Journal of Physical Distribution \& Logistics Management, 28(1), pp. 5-17. https://doi.org/10.1108/09600039810205935

Gal, T. (1995) "Postoptimal Analyses, Parametric Programming, and Related Topics", 2nd ed., Walter de Gruyter, Berlin-New York.
Handfield, R., Walton, S. V., Sroufe, R., Melnyk, S. A. (2002) "Applying environmental criteria to supplier assessment: A study in the application of the analytical hierarchy process", European Journal of Operational Research, 141(1), pp. 70-87. https://doi.org/10.1016/S0377-2217(01)00261-2

Hashemi, S. H., Karimi, A., Tavana, M. (2015) "An integrated green supplier selection approach with analytic network process and improved Grey relational analysis", International Journal of Production Economics, 159, pp. 178-191. https://doi.org/10.1016/j.ijpe.2014.09.027

Ho, W., Xu, X., Dey, P. K. (2010) "Multi-criteria decision making approaches for supplier evaluation and selection: A literature review", European Journal of Operational Research, 202(1), pp. 16-24. https://doi.org/10.1016/j.ejor.2009.05.009

Hsu, C.-W., Hu, A. H. (2009) "Applying hazardous substance management to supplier selection using analytic network process", Journal of Cleaner Production, 17(2), pp. 255-264.

https://doi.org/10.1016/j.jclepro.2008.05.004

Humphreys, P. K., Wong, Y. K., Chan, F. T. S. (2003) "Integrating environmental criteria into the supplier selection process", Journal of Materials Processing Technology, 138(1-3), pp. 349-356. https://doi.org/10.1016/S0924-0136(03)00097-9

Jahanshahloo, G. R., Hosseinzadeh Lotfi, F., Khanmohammadi, M., Kazemimanesh, M., Rezaie, V. (2010) "Ranking of units by positive ideal $D M U$ with common weights", Expert Systems with Applications, 37(12), pp. 7483-7488.

https://doi.org/10.1016/j.eswa.2010.04.011

Kao, C., Hung, H.-T. (2005) "Data envelopment analysis with common weights: the compromise solution approach", Journal of the Operational Research Society, 56(10), pp. 1196-1203. https://doi.org/10.1057/palgrave.jors.2601924

Knudsen, M. P., Servais, P. (2007) "Analyzing internationalization configurations of SME's: The purchaser's perspective", Journal of Purchasing and Supply Management, 13(2), pp. 137-151. https://doi.org/10.1016/j.pursup.2007.06.002

Koltai, T., Lozano, S., Uzonyi-Kecskés, J., Moreno, P. (2017) "Evaluation of the results of a production simulation game using a dynamic DEA approach", Computers \& Industrial Engineering, 105, pp. $1-11$.

https://doi.org/10.1016/j.cie.2016.12.048

Kraljic, P. (1983) "Purchasing must become supply management", Harvard Business Review, September/October, pp. 109-117.

Krause, D. R., Vachon, S., Klassen, R. D. (2009) "Special topic forum on sustainable supply chain management: introduction and reflections on the role of purchasing management", Journal of Supply Chain Management, 45(4), pp. 18-25. https://doi.org/10.1111/j.1745-493X.2009.03173.x

Kumar Kar, A., Pani A. K. (2014) "Exploring the importance of different supplier selection criteria", Management Research Review, 37(1), pp. 89-105.

https://doi.org/10.1108/MRR-10-2012-0230

Liu, F.-H. F., Peng, H.-H. (2008) "Ranking of units on the DEA frontier with common weights", Computers \& Operations Research, 35(5), pp. $1624-1637$. https://doi.org/10.1016/j.cor.2006.09.006 
Liu, F., H.F., Peng, H.-H., Chang, H.-W. (2006) "Ranking DEA efficient units with the most compromising common weights", In: The Sixth International Symposium on Operations Research and Its Applications (ISORA '06), Xinjiang, China, pp. 219-234.

Markovits-Somogyi, R., Gecse, G., Bokor, Z. (2011) "Basic efficiency measurement of Hungarian logistics centres using data envelopment analysis", Periodica Polytechnica Social and Management Sciences, 19(2), pp. 97-101.

https://doi.org/10.3311/pp.so.2011-2.06

Markovits-Somogyi, R. (2011) "Data envelopment analysis and its key variants utilized in the transport sector", Periodica Polytechnica Transportation Engineering, 39(2), pp. 63-68. https://doi.org/10.3311/pp.tr.2011-2.03

Martos, B. (1964) "Hyperbolic programming", Naval Research Logistics Quarterly, 11(2) pp. 135-155. https://doi.org/10.1002/nav.3800110204

Morrissey, B., Pittaway, L. (2004) "A study of procurement behaviour in small firms", Journal of Small Business and Enterprise Development, 11(2), pp. 252-264. https://doi.org/10.1108/14626000410537191

Narasimhan, R., Talluri, S., Mendez, D. (2001) "Supplier Evaluation and Rationalization via Data Envelopment Analysis: An Empirical Examination", Journal of Supply Chain Management, 37(2), pp. 28-37. https://doi.org/10.1111/j.1745-493X.2001.tb00103.x

Noci, G. (1997) "Designing "green" vendor rating systems for the assessment of a supplier's environmental performance", European Journal of Purchasing and Supply Management, 3(2), pp. 103-114. https://doi.org/10.1016/S0969-7012(96)00021-4

Rezaei, J., Nispeling, T., Sarkis, J., Tavasszy, L. (2016) "A supplier selection life cycle approach integrating traditional and environmental criteria using the best worst method", Journal of Cleaner Production, 135, pp. 577-588.

https://doi.org/10.1016/j.jclepro.2016.06.125
Roll, Y., Golany, B. (1993) "Alternate methods of treating factor weights in DEA", Omega, 21(1), pp. 99-109. https://doi.org/10.1016/0305-0483(93)90042-J

Sinha, A. K., Anand, A. (2017) "Towards fuzzy preference relationship based on decision making approach to access the performance of suppliers in environmental conscious manufacturing domain", Computers \& Industrial Engineering, 105, pp. 39-54. https://doi.org/10.1016/j.cie.2016.12.033

Simić, D., Kovačević, I., Svirčević, V., Simić, S. (2017) "50 years of fuzzy set theory and models for supplier assessment and selection: A literature review", Journal of Applied Logic, 24m pp. 85-96. https://doi.org/10.1016/j.jal.2016.11.016

Stannack, P., Osborn, M. (1997) "The Politics of Vendor Assessment, in: Emerging Issues in Purchasing and Supply Chain Management", IFPMM Publications, 1, pp. 197-205.

Talluri, S., Narasimhan, R. (2004) "A methodology for strategic sourcing", European Journal of Operational Research, 154(1), pp. $236-250$. https://doi.org/10.1016/S0377-2217(02)00649-5

Van Weele, A. J. (2009) "Purchasing and Supply Chain Management: Analysis, Strategy, Planning and Practice", 5th ed., Cengage Learning, United Kingdom.

Weber, C. A., Current, J. R., Benton, W. C. (1991) "Vendor selection criteria and methods", European Journal of Operational Research, 50(1), pp. 2-18.

https://doi.org/10.1016/0377-2217(91)90033-R 